\title{
BMJ Open How do residents perceive and narrate stories about communication challenges in patient encounters? A narrative study
}

\author{
Jane Ege Møller, ${ }^{1}$ Matilde Nisbeth Brøgger ${ }^{2}$
}

To cite: Møller JE, Brøgger MN. How do residents perceive and narrate stories about communication challenges in patient encounters? A narrative study. BMJ Open 2019;9:e029022. doi:10.1136/ bmjopen-2019-029022

- Prepublication history for this paper is available online. To view these files, please visit the journal online (http://dx.doi. org/10.1136/bmjopen-2019029022).

Received 8 January 2019 Revised 29 March 2019 Accepted 14 May 2019

\section{Check for updates}

(c) Author(s) (or their employer(s)) 2019. Re-use permitted under CC BY-NC. No commercial re-use. See rights and permissions. Published by BMJ.

${ }^{1}$ Center for Health Sciences Education, Aarhus University, Aarhus C, Denmark

${ }^{2}$ School of Communication and Culture, Aarhus University, Aarhus C, Denmark

Correspondence to Dr Jane Ege Møller; Jane@cesu.au.dk

\section{ABSTRACT}

Objective This article investigated residents' narratives to gain their understandings of which patterns are challenging in doctor-patient conversations.

Design Qualitative narratological framework.

Participants We analysed 259 narratives from 138 residents' oral recounts of communication with patients in which they had felt challenged.

Results The analysis identified an ideal narrative for the doctor-patient encounter with the resident as protagonist pursuing the object of helping the patient with his health problem. Disruptions of this ideal narrative were at play when challenges occurred. Regardless of medical setting, challenges were often related to the establishment of a common object, and the communication actants had to go through negotiations, disagreements or even battles when trying to reach a common object. Challenges also occurred when actants which in the ideal narrative should act as helpers become opponents. We find narratives where patients, relatives and colleagues become opponents. Conclusions Our study showed that communication challenges were the result of disruptions of the perceived ideal narrative. Residents found it especially challenging to establish a common object, and dealing with helpers turned opponents. Patient communication is thus a challenge in the transition phase from student to doctor, and doctor-patient communication is complex in nature and continuously perceived to be so by residents, despite pregraduate training.

\section{INTRODUCTION}

Doctors' communication skills have been the focus of extensive research, both with respect to teaching and assessing communication skills. ${ }^{1-4}$ Nowadays, it is understood that communication skills can be learnt by medical practitioners, ${ }^{5-7}$ and that good communication skills have a positive influence on patients' satisfaction and health outcomes. $^{8-11}$

Many studies focus on whether doctors' feel that they have the necessary skills, for example, self-efficacy. ${ }^{12} 13$ Fewer studies have investigated doctors' communication challenges. Some report on these challenges using categories such as effectively exchanging information with patients,

\section{Strengths and limitations of this study}

The narrative framework enabled a unique insight into challenging doctor-patient communication as seen through the eyes of the resident.

- The novel use of Greimas' actantial model helped to provide a framework for an in-depth understanding of the key patterns of the residents' narratives about communication challenges.

- Despite the researchers being involved in the courses from which the material was collected, transparent discussion and iterative data analysis reassured us that multiple interpretations had been considered.

- Although a majority of the cases were from a general practice setting, the large number of residents included, combined with the varied fields of clinical specialties they seek, enhanced the transferability of the findings

- Despite our material consisting of cases presented for a specific learning situation, and not more detailed narratives told in interviews, the richness of the many short narratives compensated for this lack of narrative depth.

negotiating terms of the encounter ${ }^{14}$ and managing emotional aspects of the patient encounter, ${ }^{14-16}$ while others conclude that breaking bad news, structuring the conversation, ${ }^{141617}$ exploring patients' perspectives or health beliefs, ${ }^{15} 17$ negotiating disagreements, motivating behavioural changes and discussing psychosocial ailments ${ }^{15}$ are challenging aspects of doctor-patient communication. While it is valuable to know which types and aspects of communication doctors find challenging, more in-depth knowledge about how these challenges unfold is needed to be able to transform such knowledge into specific skills. Therefore, to add value to the already identified themes, a narrative approach is relevant because it provides a framework for grasping discourse patterns in a detailed way. In a study, Skjørshammer shows how narrative analysis is an effective strategy for gaining in-depth understanding of conflicts among health professionals. ${ }^{18}$ 
To our knowledge, only one study ${ }^{15}$ that used a narrative approach to investigate doctors' perspectives of communication challenges in patient encounters has been conducted; this involved doctor's participating in a conference on teaching medical interviewing, that is, participants with an interest in communication.

Here, we are interested in self-reported communication challenges as opposed to challenges identified through observation for example. Gaining knowledge about what trainee doctors themselves find challenging is important in order to gain a deeper understanding of the doctor's first-person perspective. Studies of self-reported communication challenges have either had medical students ${ }^{1416}$ or experienced clinicians ${ }^{15}$ as their respondents. Only Perron ${ }^{17}$ investigated residents' perceived needs. In the light of research demonstrating a decline of communication skills over time, ${ }^{517}{ }^{19}$ it is important to identify communication challenges at this stage where residents start to get clinical experience. An in-depth understanding of the complex discourse patterns which trainee doctors find challenging would enable educators to design communication skills teaching tailored to these patterns. For continuous education skills training to be perceived as relevant, it is necessary to have knowledge of doctors' self-reported challenges, and thus their needs.

Therefore, this study aims to answer the following research question: How do residents perceive and narrate stories about communication challenges in patient encounters?

\section{METHOD \\ Design}

The study uses a qualitative design with a narrative approach for analysing recorded resident stories about communication challenges.

\section{Participants and material}

Our empirical material stems from obligatory Danish communication courses for residents. In Denmark, residency training is organised in two periods of 6 months, where residents shift between different medical specialties and departments. The first period consists of different types of hospital training, for example, emergency department. In the second period, $80 \%$ of the residents are in general practice, $10 \%$ in psychiatric settings and $10 \%$ in other hospital settings. The mandatory 3-day communication skills training course takes place during the second period, which means that all participants were about $6-8$ months into their first year of residency. The general gender distribution is $65 \%$ women and $35 \%$ men. The course does not involve any summative feedback or tests; participants complete the course by active participation. Prior to this, all medical students participate in pregraduate communication skills training in medical school. As preparation for the resident courses, participants are asked to present 'two concrete communication situations in which they felt challenged'. In the given instruction, it has been a deliberate choice not to define a 'challenge' for the participants. Instead, the purpose is to let the residents themselves identify challenging patient communication from their perspective. Course participants share these two situations orally in a so-called "case round', where facilitators invite each participant to share their stories with their peers (15 participants per course). The residents tell their stories in their own words and structure, and the facilitator only contributes with a few clarifying questions and comments. The stories are told briefly (3-12 min) and are subsequently used as a basis for roleplay and reflection exercises. The authors of this article both teach these courses but were never involved in facilitating the case rounds. From May to November 2017, we made audio-recordings and video-recordings of 10 case rounds. Because of the brevity of the stories, we aimed for high number in order to substantiate the findings and add to the trustworthiness. All recordings were transcribed verbatim.

\section{Ethics}

The participants were informed of the authors' confidentiality agreements, the assurance of participant anonymity and how the data would be presented. It was emphasised that participation was optional. In addition, written informed consent was obtained from all the participants and they were asked for permission to audio-record and video-record their stories. The study was excepted from approval by The Central Denmark Region Committees on Health Research Ethics, according to the Consolidation Act on Research Ethics Review of Health Research Projects.

\section{Patient and public involvement}

No patients or public were involved in this study.

\section{Theoretical framework}

We used a narratological framework to grasp the key patterns of what residents perceived to be challenges in their doctor-patient encounters. A narrative approach is commonly used to gain insights into questions about health and illness from doctors' and patients' perspectives. Vanderford et $a l,^{15}$ for example, analysed the key narrative features of clinicians' stories about communication challenges. Furthermore, several medical educators have stressed the importance of doctors and medical students telling their stories—-mainly through reflexive writingto give them narrative competence and help them retain their empathy. ${ }^{20-23}$ Studies of medical students' written narratives have provided insight into professional formation and the hidden curriculum. ${ }^{24}{ }^{25}$ Often, narrative analysis is used to explore patients' illness narratives, for example, patients (dis)satisfaction with communication as seen in the narrative medicine movement, ${ }^{26-28}$ or carers' narratives. ${ }^{29}$ In a study of patient narratives, Lucius-Hoene $e t a \vec{P}^{30}$ provided an analysis of how patients verbally constructed their doctors by giving them a voice in narrated scenes of encounters, and Denniston $e t a l^{31}$ 


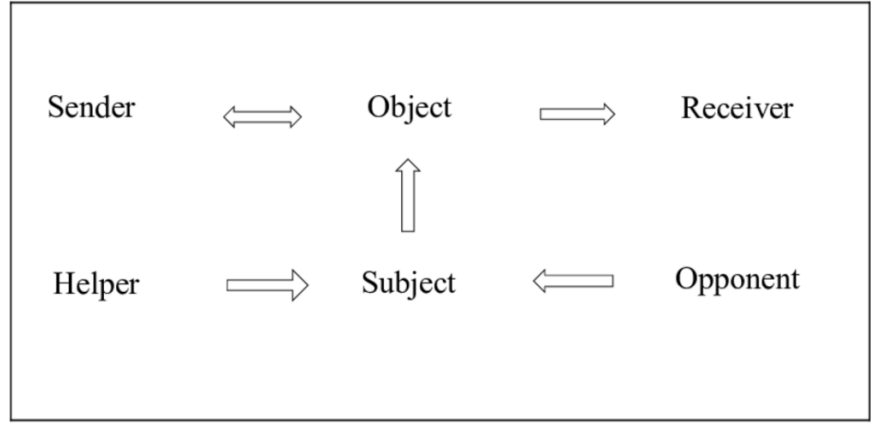

Figure 1 The actantial model.

grasped patient (dis)satisfaction patterns using a narrative lens.

The focus of this article is on inexperienced doctors' perspectives on communication challenges. Our analysis provides insights into how residents construct their patients, themselves and their colleagues in narratives by assigning perceived characters, functions and roles to them. Greimas' actantial model offers a semantic scheme for analysing the ways in which a narrative unfolds. ${ }^{32}$ The actantial model (see figure 1) consists of six different actants, that is, functions that are related in three different axes: the axis of desire, the axis of power and the axis of knowledge. The model breaks down the actions in the narrative and provides an analytical tool for understanding what desires and relations initiate the project of the protagonist, that is, 'the subject's striving for 'the object'. The helper and the opponent, which each represent solutions and hindrances for achieving the object, compose the axis of power. In the knowledge axis, the sender instigates the action, whereas the receiver benefits from the action, and is the receiver of the object. The model enabled us to analyse the plot and key roles in the communication challenge narratives the residents provided.

The actantial model has been used successfully in health research, for example, for analysis of written health communication, such as studies of health promotion pamphlets ${ }^{33}$ and online patient forums. ${ }^{34}$ In addition, Gwyn ${ }^{35}$ emphasises the explanatory powers of the model in analysing patients' illness narratives.

\section{Data analysis}

In the first step of the analysis, both authors read the transcribed material from 134 cases. This material stemmed from the first five courses observed (half of the courses), and these were thus chosen using a principle of convenience sampling. ${ }^{36}$ Data familiarisation was achieved by this reading. We independently tabulated issues into initial salient themes by an open and inductive reading (eg, 'patients opposing treatment plan' or 'residents feeling unable to control the conversation') by writing themes in the transcription. This led us to apply the Greimas actantial model in order to grasp the structural elements that moved the story forwards. We then read the material again, this time sitting together and applying the six
Table 1 Overview of cases and clinical settings

Number of residents 138

Number of cases 259

Clinical setting Psychiatric ward and outpatient clinic: $19(7.3 \%)$

Accident and emergency department: $39(15.1 \%)$

Somatic ward: $30(11.6 \%)$

Somatic outpatient clinic: 7 (2.7\%)

General practice: 164 (63.3\%)

elements of the actantial model for each case (same 134 cases) in a more deductive process. Through this analytical step, we identified the dominant discursive patterns which are presented in the results. For the remaining 125 cases (the last five courses observed), we coded the material separately still using the actantial model, in order to compare these data with our first analysis, and to identify possible new narrative patterns and variations within them. This supported the trustworthiness of our findings. Finally, we sat together and discussed concerns about the interpretations, solved disagreements and identified key patterns in the material. Overall, this allowed for an iterative analysis process with both inductive and deductive elements.

\section{RESULTS}

In the following, we present our findings, supplemented with illustrative quotations from the cases in order to increase the transparency of our interpretations. All quotations have been translated from Danish into idiomatic English. We have a total of 259 cases from 138 residents (see table 1). The length of the stories varied from 3 to $12 \mathrm{~min}$.

\section{The ideal story}

Based on the analysis, we identified an ideal narrative for the doctor-patient encounter (see figure 2). This is to be understood as the residents' implicit understandings and expectations of how the narrative should ideally unfold. In the ideal narrative, the resident is the protagonist and subject pursuing the object of helping the patient with his

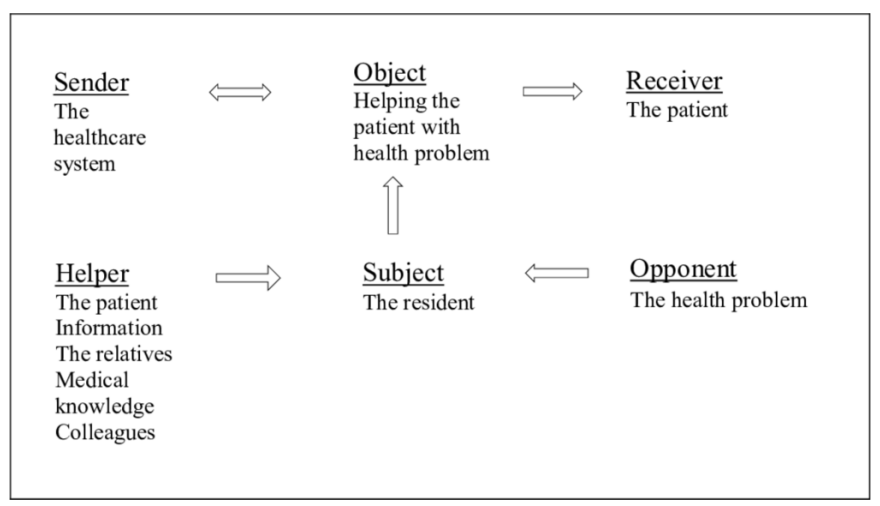

Figure 2 Actantial model analysis - the ideal narrative. 
Table 2 Overview of narrative patterns related to communication challenges

\begin{tabular}{ll}
\hline Main pattern & Subpattern \\
\hline $\begin{array}{l}\text { Object-related } \\
\text { challenges }\end{array}$ & $\begin{array}{l}\text { Object negotiations } \\
\text { Object disagreements } \\
\text { Object battles }\end{array}$ \\
Helpers as & $\begin{array}{l}\text { Patients as opponents } \\
\text { opponents }\end{array}$ \\
& $\begin{array}{l}\text { Patients challenge medical authority } \\
\text { Relatives as opponents } \\
\text { Colleagues as opponents }\end{array}$ \\
\hline
\end{tabular}

health problem. The sender is the healthcare system as a whole, and the receiver is the patient. Typical helpers are the patient, the information they provide, their relatives, biomedical knowledge and colleagues. The opponent is the health problem. A part of this ideal narrative is the patient's acceptance of the resident as helper. Disruptions of this ideal narrative are at play when challenges occur.

\section{The dynamic object}

Because the very object that the residents pursue is 'helping the patient with his health problem', it follows that this is not a stable or unambiguous entity. The quest of the doctor is to identify both what helping means in each encounter and what the patient's health problem entails. The patient and doctor must agree on the exact content in order for the doctor to achieve the object. In the material, communication challenges often revolved around different types of object negotiation, disagreement and sometimes even battles (see table 2). This is a continuum that always involved a change in the ideal narrative distribution of roles and functions in the narrative.

\section{The object negotiation}

The material showed how different types of negotiation between residents and patients took place. Sometimes the resident found out so late in the conversation what the object was for the patient that providing help was difficult, for example, in follow-up conversations where the patient's agenda turned out to be different than previously agreed. Another pattern was when patients had too many problems (or objects), and the resident did not have enough time and suggested prioritising:

The patient had 5 problems she wanted me to take a look at and because she showed up late, we only had 5 min. I tried to explain that we did not have the time to deal with all the problems properly, but she never understood

Misunderstandings occurred due to differences between lay and medical perceptions of what caused the illness. Occasionally, the patient had a mistaken perception of the cause of the problem which created barriers for mutual understanding of the object.

Furthermore, recurrent themes of negotiation took the form of the patient not being happy with or convinced by the resident's suggestions. This was witnessed in statements such as 'My suggestions never seemed good enough for the patient, even though she wanted my help'.

\section{The object disagreement}

A second pattern related to disagreement between patients and residents about what the object was. A recurrent theme was that the patient believed that their problem would be solved by investigations, like an MRI scan or treatments, and made demands, as witnessed in this quote: 'I actually thought that I had a good plan, but the patient didn't agree'. Or when residents identified the solution to the patient's problem as being healthy behaviours, for example, taking prescribed medication, adapting healthy behaviours and abandoning unhealthy ones, and the patients disagreed. As one resident explained about a young psychiatric patient, 'He couldn't see any reason to stop smoking hash or start taking his medication, because he didn't think he was ill in any way'.

Another dimension to these disagreement patterns arose when patients who disagreed with the resident's suggestions appealed to the helping role of the resident. An example was a resident reluctant to increase a patient's medication, but the patient insisted: 'so what you want is that I should just walk around in pain?! It can't be right!'. Statements such as these where patients explicitly addressed the resident's obligation as helper, and at the same time, refused their help, caused frustration among the residents.

Another aspect that led to disagreements related to the degree to which the patient was sick. For the narrative to move along without challenges, the patient needed to be sick enough to fulfil the role of receiver of the object (help). As one resident stated, 'I think it is difficult when patients are not really sick, but think they are'. It was difficult communicating with these patients that they were not really entitled to the help: 'There is not a damn thing wrong with them, and the problem is how to tell them that there is no reason that we look at everything thoroughly'. Furthermore, patients who had been through all tests without diagnosis, and there was nothing left for the doctor to offer them, were found to be communicatively challenging. As one resident said, 'What do you do then, how do you help them, without actually doing anything?'.

The opposite situation was seen as equally challenging, that is, communication with patients who were too sick, and did not want help. Moreover, patients who were sick but did not recognise it were seen as challenging communication partners. For example, residents stated that it was more difficult to break bad news to patients who were not expecting it than those who had felt unwell.

\section{The object battle}

The residents described how disagreements could develop into actual battles, where residents and patients/ relatives openly fought about what the object was. Here, there were two types of narratives: (1) the resident 'wins' the definition of the object, and (2) the patient 'wins' the definition of the object. 
When residents stuck to their medical judgement and did not yield to patients' demands, they seemed to win the definition of the object. This was observed in narratives where patients 'attacked' residents if their view of the problem and solution was not the same as the patient's. This was expressed in the following narrative:

The patient just keeps going on and on - pushing me for a scan. And she gets angry and we talk about what a poor doctor I am. I get angry too, because she doesn't listen to me. So, I ask my supervisor to come and give his advice, but before he gets there, the patient leaves in anger.

In these battle narratives, a key challenge was how to 'stick to one's professional competence and medical knowledge' in defining the object, and at the same time make the patient see that one was actually helping. In addition, a common paradox was that even though the resident might win the right to define the object, they could not achieve their goal: if the resident won the battle, the patient did not feel helped, and the residents recalled verbal 'attacks' from patients like 'you don't want to help me', or 'this is not helping me'.

In other narratives, the ending was different; here, the patient won the right to define the object and residents prescribed treatments and referred to tests for which they did not find medical indications. These narratives were about surrender and loss of control, and they were told with equal amounts of sorrow and self-irony, sometimes even with an acute loss of words:

She puts so much pressure on me that in the end I lose all control and I can't even find any arguments for why we can't just do these blood samples and tests straight away. I am totally thrown off, I don't even know how to... I mean what should I say? I just sit there and say 'er, mmm, er' and I almost started crying because I completely lost myself. Because she was so insistent, I felt I completely lost my power and medical authority. It was a horrible feeling.

An additional pattern was when residents turned to their supervisor in the hope that they would support their medical decision, but they did not:

And my supervisor told me just to give them a - I believe he called it 'a shut-up ECG'. And there was in no way any indication for it, but I guess that was the solution, then.

Taken together, these negotiations, disagreements and battles over the object involved a shift in the ideal roles of helper and opponent during the consultation. Helpers occasionally became opponents which resulted in ideal 'helping' narratives transforming into narratives of conflict making the residents surprised and overwhelmed when helpers suddenly turned out to be opponents.

\section{When helpers become opponents}

As shown above, the transformation of helpers to opponents occasionally relates to different understandings of the 'content' of the object. However, other patterns of helper-opponent role transformations were identified, where expected helpers, for example, patients, relatives and colleagues, occasionally became opponents and thus challenges in the communication, for example, due to patients perceiving the residents as too young, etc (see table 2). In the following, we present examples of patients as opponents.

\section{Patients as opponents}

One way in which patients became the opponent related to the amount of their speech. In order for the doctor to fulfil the object of the narrative, she needed a sufficient amount of relevant information at the right time. Both patients who talked too much and too little created communication problems. The instances of communication challenges linked to patients' excessive speech were filled with utterances linked to straying away from the central path of the narrative, such as patients who explained 'east and west', 'jumped from one thing to another', with doctors trying to 'get back to the story', 'back on track' and 'move him on'. When patients did not conform to the desired speech behaviour by talking excessively, doctors felt they lost control of the conversation. The problem was exacerbated when doctors were unable to stop the patient, because they found listening to be the best way to support the patient, to give the patient space and to avoid insulting the patient. These conversations became excessively long as they seemed 'to drag out' with consequences for the doctor's time: 'it takes $30 \mathrm{~min}$ to talk to him about something that should take $15 \mathrm{~min}$ '. Furthermore, analysis revealed examples where doctors found that patients not only talked excessively, but the content of their speech was also irrelevant.

The opposite variant was the quiet patient. One resident described the consequences of sitting opposite a quiet patient as the inability to 'get to the core of his problems', and to find out 'what his struggles are'. In this case, inability to get the patient to talk made the doctor feel incompetent in the patient's eyes. Similarly, after having delivered bad news, a patient did not react: he was 'stonefaced'. The doctor felt upset that she could not 'open up' the patient. The communication challenges linked to quiet patients could thus make doctors feel inadequate, making it difficult to resurrect a fruitful conversation: 'I think he has some things that he would like to share, but he doesn't know how to open up, and neither do I'. This lack of mutual communication led to lack of progress in the communication 'I get nowhere', and the doctor felt unable to reach the patient, similar to the above example of reaching the core.

\section{Patients challenge medical authority}

In some narratives, patients seemed to oppose the resident's authority or role both indirectly and directly. 
Indirect opposition was evident when residents were met by what they interpreted as a condescending style of communication, such as 'you look very sweet, my dear, but let me tell you ...', or 'he keeps calling me 'little guy' throughout the consultation: 'Can't you see that I am in pain, little guy', and so on'. Attacks that were more direct were witnessed in stories where the patient openly showed hostility to the resident. 'The patient is very hostile from the beginning, and says that I am stupid and incompetent. I look deep into my 'communication toolkit' and out of my mouth I hear something like 'I think we are talking past each other here,' and he says, 'You are bloody right we are-no wonder as you are so stupid.'

Occasionally, this had the character of a fictive opponent in the inner world of the resident without the patient explicitly mentioning it. This is seen in residents' quotes such as 'My impression was that he thought that I was completely useless and 'she is just a young idiot'. That was how I felt in our meeting'.

\section{Relatives as opponents}

Relatives acted as opponents both in the consultation setting and by contacting the resident on their own afterwards. A resident spoke about three frustrated relatives: 'They demanded a lot of things, all of which were impossible to accommodate. And I thought it was difficult to figure out what to do, because they said things like 'We have heard that you can get a scan for this and for that' and they had so many demands and were really angry.'

\section{Colleagues as opponents}

Colleagues could also become opponents, which indicated that residents sometimes were part of other people's narratives. Examples of this were patients who were referred from general practice to the hospital for no obvious reason, or patients insisting on specific orders from the GP, as in this quote: 'and my feeling was that either the GP is bloody annoying or she has run out of possibilities'. Another pattern was when senior doctors took over consultations instead of helping residents with advice that would enable them to perform themselves:

And $15 \mathrm{~min}$ before we are supposed to go home, the radiologist calls and says that the patient has many tumors everywhere. The woman doesn't have any relatives, and I wonder how to tell her, with only $15 \mathrm{~min}$ left of the day. So, I consult my older colleague to get help with how to do it. My colleague ends up being angry with me, and asked why I come in with such a message so late in the afternoon and she says that I should just leave, she'll take the conversation herself.

\section{DISCUSSION}

Our study provides knowledge of how patient communication is a challenge in the transitional phase from student to doctor. The narratological approach enabled us to identify an ideal narrative for doctor-patient communication with the resident as protagonist pursuing the object of helping the patient with his health problem. Results showed that, regardless of medical setting, challenges were often related to the establishment of a common object, which could be further encumbered by various opponents such as the patient him/herself, relatives or colleagues.

Our study highlights the ways in which patient communication is a challenge in the transitional phase from student to doctor. The narratives showed that communication challenges existed in different clinical settings and in a variety of ways. Previous studies have identified other challenges in this phase, such as increased responsibility, uncertainty, lack of support, medical knowledge and credibility. ${ }^{37-39}$ We have added to this picture by showing that communication is a dimension where these challenges find concrete expression, for example, when colleagues become opponents or when residents' feel that their medical authority is questioned. Luthy $e t a t^{40}$ also identified communication problems as a challenge in this phase; however, these mainly related to difficulties in communicating with colleagues. Our study sheds further light on how communication with patients and relatives is an additional challenge, and how all these different actants (resident, patients as well as colleagues) are related, connected and undergo transformation.

Our findings indicate that a dimension of 'the ideal narrative' is a kind of 'social script ${ }^{\text {,1 }}$ for doctor-patient consultations in which certain discursive patterns of patients are anticipated by the residents. We observed this in the narrow margin for acceptable levels of patient speech: too much and too little talk made the doctor feel unable to fulfil the object of the encounter. Deviations often led to confusion for the residents, which demonstrates a more vulnerable side of being a doctor than the more traditional understanding of the doctor as having absolute power and control in patient meetings. Thus, our findings point out how doctors may feel devaluated and insecure in challenging patient meetings, which interestingly mirrors how patients feel when experiencing conflicts with doctors. ${ }^{31}$

This study has focused solely on the perspective of the trainee doctors. It would have been interesting to compare their narratives with those of patients. This would have enabled an analysis that captured the dynamics of how narratives are not only static expressions of positions but a part of 'positioning' each other as something, for example, specific kinds of doctor or patient. ${ }^{42}$ It seems that these challenges could be examples of how patients (and relatives) in their pursuit of objects meet givers and helpers who also transform into opponents. However, this type of analysis was not possible due to the scope of this study, but would be an interesting focus for further research.

The findings of this study may be limited to the Danish context and its specific organisation of postgraduate medical education. As mentioned, the majority of residents in this study worked in general practice, hence 
the over-representation of stories from this context. Narratives from other settings, especially psychiatry and A\&E, are represented, whereas other hospital narratives are few. Furthermore, Denmark is one of the few countries that has a mandatory communication skills training course for all residents (3 days); thus, communication challenges may be more visible for them than in countries without this postgraduate structure. Our material consists of cases that were presented for a specific learning situation, not narratives told in interviews. This is a methodological limitation because it prevented us from asking follow-up questions potentially leading to more detailed and nuanced narratives. However, we found that the richness of our many short narratives compensated for this lack of narrative depth.

The patterns we identified in the analysis confirm the findings of Vanderford $e t a l^{12}$ who found communication challenges when storytellers' expectations concerning appropriate norms were violated. Our observed object negotiations also resonate with their findings that patients who sought medical solutions were resistant when physicians recommended behavioural changes instead. Vanderford $e t a l$ s study indicates that our findings concerning residents' perceived challenges may be recognised by senior doctors, too.

We have shown that despite pregraduate communication skills training, residents still experienced communication competencies as inadequate. This points to the importance of continuing communication skills training, not only as part of pregraduate training, but also in postgraduate training and continuous medical education. ${ }^{54}$ Moreover, our findings suggest the importance of postgraduate training with a focus on specific skills, such as identifying patient's problem, negotiating agenda, taking both patient's and physician's needs into account, supporting the patient in being focused, etc. Our findings illustrate that communication situations between patients and doctors are complex in nature and are perceived to be so by residents, despite pregraduate training. Therefore, this complexity should be the focus of future developments in both communication skills education and research.

Contributors JEM and MNB were both involved in the conception and design of the work, the analysis and interpretation of data for the work and the drafting and revision of the article.

Funding This work was supported by an AUFF Starting Grant grant number AUFFE-2015-FLS-7-30. The researchers were independent from the funders.

Disclaimer The funder had no involvement in the study design, collection, analysis and interpretation of data, the writing of the report or the decision to submit the article for publication.

Competing interests None declared.

Patient consent for publication Not required.

Ethics approval The study was approved by the Danish Data Protection Agency. The study was excepted from approval by The Central Denmark Region Committees on Health Research Ethics, according to the Consolidation Act on Research Ethics Review of Health Research Projects.

Provenance and peer review Not commissioned; externally peer reviewed.
Data sharing statement We do not have ethics approval to share raw data from our interviews.

Open access This is an open access article distributed in accordance with the Creative Commons Attribution Non Commercial (CC BY-NC 4.0) license, which permits others to distribute, remix, adapt, build upon this work non-commercially, and license their derivative works on different terms, provided the original work is properly cited, appropriate credit is given, any changes made indicated, and the use is non-commercial. See: http://creativecommons.org/licenses/by-nc/4.0/.

\section{REFERENCES}

1. Silverman J, Kurtz SM, Draper J. Skills for communicating with patients. 3rd edn. London, New York: Radcliffe Publishing, 2013.

2. Kurtz S, Silverman J, Draper J. Teaching and learning communication skills in medicine. Oxford: Radcliffe, 2005.

3. Essers G, van Dulmen S, van Es J, et al. Context factors in consultations of general practitioner trainees and their impact on communication assessment in the authentic setting. Patient Educ Couns 2013;93:567-72.

4. Zick A, Granieri M, Makoul G. First-year medical students' assessment of their own communication skills: a video-based, openended approach. Patient Educ Couns 2007;68:161-6.

5. Aspegren K. BEME Guide No. 2: Teaching and learning communication skills in medicine-a review with quality grading of articles. Med Teach 1999;21:563-70.

6. Langewitz WA, Eich P, Kiss A, et al. Improving communication skills-a randomized controlled behaviorally oriented intervention study for residents in internal medicine. Psychosom Med 1998;60:268-76.

7. Kaufman DM, Laidlaw TA, Macleod H. Communication skills in medical school: exposure, confidence, and performance. Acad Med 2000;75:S90.

8. Boissy A, Windover AK, Bokar D, et al. Communication Skills Training for Physicians Improves Patient Satisfaction. J Gen Intern Med 2016;31:755-61.

9. Maguire P, Pitceathly C. Key communication skills and how to acquire them. BMJ 2002;325:697-700.

10. Stein T, Frankel RM, Krupat E. Enhancing clinician communication skills in a large healthcare organization: a longitudinal case study. Patient Educ Couns 2005;58:4-12.

11. Brown RF, Bylund CL. Communication skills training: describing a new conceptual model. Acad Med 2008;83:37-44.

12. Gude T, Finset A, Anvik T, et al. Do medical students and young physicians assess reliably their self-efficacy regarding communication skills? A prospective study from end of medical school until end of internship. BMC Med Educ 2017;17:107.

13. Axboe MK, Christensen KS, Kofoed PE, et al. Development and validation of a self-efficacy questionnaire (SE-12) measuring the clinical communication skills of health care professionals. BMC Med Educ 2016;16:272.

14. Braverman G, Bereknyei Merrell S, Bruce JS, et al. Finding the Words: Medical Students' Reflections on Communication Challenges in Clinic. Fam Med 2016;48:775-83.

15. Vanderford ML, Stein T, Sheeler R, et al. Communication challenges for experienced clinicians: topics for an advanced communication curriculum. Health Commun 2001;13:261-84.

16. Peters S, Young K, McCracken $\mathrm{C}$. What do medical trainees think is so difficult about communicating with patients? Patient Educ Couns 2011;85:e150-4.

17. Junod Perron N, Sommer J, Hudelson P, et al. Residents' perceived needs in communication skills training across in- and outpatient clinical settings. Educ Health Abingdon Engl 2009;22:280.

18. Skjørshammer M. Understanding conflicts between health professionals: a narrative approach. Qual Health Res 2002;12:915-31.

19. van Dalen J, Kerkhofs E, van Knippenberg-Van Den Berg BW, et al. Longitudinal and concentrated communication skills programmes: two dutch medical schools compared. Adv Health Sci Educ Theory Pract 2002;7:29-40.

20. Childress MD. From Doctors' Stories to Doctors' Stories, and Back Again. AMA J Ethics 2017;19:272.

21. Hunter KM. Doctors' stories: the narrative structure of medical knowledge. Princeton, NJ: Princeton Univ, 1991.

22. Rabin S, Maoz B, Elata-Alster G. Doctors' narratives in Balint groups. Br J Med Psychol 1999;72:121-5.

23. Charon R, Hermann N, Devlin MJ. Close Reading and Creative Writing in Clinical Education: Teaching Attention, Representation, and Affiliation. Acad Med 2016;91:345-50. 
24. Kissler MJ, Saxton B, Nuila R, et al. Professional Formation in the Gross Anatomy Lab and Narrative Medicine. Academic Medicine 2016;91:772-7.

25. Gaufberg EH, Batalden M, Sands R, et al. The hidden curriculum: what can we learn from third-year medical student narrative reflections? Acad Med 2010;85:1709-16

26. Charon R. Narrative medicine: honoring the stories of illness. Oxford: Oxford Univ. Press, 2008.

27. Frank AW. The wounded storyteller: body, illness, and ethics. Chicago: University of Chicago Press, 1995

28. Vindrola-Padros $C$, Johnson GA. The narrated, nonnarrated, and the disnarrated: conceptual tools for analyzing narratives in health services research. Qual Health Res 2014;24:1603-11.

29. Witham G, Haigh C, Mitchell D, et al. Carer Experience Supporting Someone With Dementia and Cancer: A Narrative Approach. Qual Health Res 2018;28:813-23.

30. Lucius-Hoene G, Thiele U, Breuning M, et al. Doctors' voices in patients' narratives: coping with emotions in storytelling. Chronic IIIn 2012;8:163-75.

31. Denniston C, Molloy E, Rees CE. 'I will never ever go back': patients' written narratives of health care communication. Med Educ 2018;52:757-71.

32. Greimas AJ. Structural semantics: an attempt at a method. Lincoln: University of Nebraska Press, 1983.

33. Askehave I, Zethsen KK. "Check it out" - the construction of patient empowerment in health promotion leaflets. English for Academic and Professional Purposes. Amsterdam, New York: Rodopi, 2010.

34. Wentzer HS, Bygholm A. Narratives of empowerment and compliance: studies of communication in online patient support groups. Int J Med Inform 2013;82:e386-94
35. Gwyn R. Communicating Health and Illness. 1 Oliver's Yard. London, United Kingdom: SAGE Publications Ltd, 2001.

36. Braun V, Clarke V. Using thematic analysis in psychology. Qual Res Psychol 2006:3:77-101.

37. Brennan N, Corrigan O, Allard J, et al. The transition from medical student to junior doctor: today's experiences of Tomorrow's Doctors. Med Educ 2010;44:449-58.

38. Lempp H, Cochrane M, Seabrook M, et al. Impact of educational preparation on medical students in transition from final year to $\mathrm{PRHO}$ year: a qualitative evaluation of final-year training following the introduction of a new year 5 curriculum in a London medical school. Med Teach 2004;26:276-8.

39. Pitkala KH, Mantyranta T. Professional socialization revised: medical students' own conceptions related to adoption of the future physician's role--a qualitative study. Med Teach 2003;25:155-60.

40. Luthy C, Perrier A, Perrin E, et al. Exploring the major difficulties perceived by residents in training: a pilot study. Swiss Med Wkly 2004;134:612-7.

41. RN SC. The Framing of culture: Interdisciplinary essays on culture theory. Fram Cult Interdiscip Essays Cult Theory Course Available Blackboard Beijing Foreign Stud Univ Stud Univ Louisville Louisville KY. 2006.

42. Harré R, Moghaddam FM. Introduction: The Self and Others in Traditional Psychology and in Positioning Theory. In: Harré R, Moghaddam FM, eds. The Self and Others: Positioning Individuals and Groups in Personal, Political and Cultural Contexts. Westport, Conn, USA: Praeger Publishers, 2003.

43. Junod Perron N, Sommer J, Louis-Simonet M, et al. Teaching communication skills: beyond wishful thinking. Swiss Med Wkly 2015;145:w14064. 